\title{
Quantifying the impacts of socio-economic factors on air quality in Chinese cities from 2000 to 2009
}

\author{
Juanjuan Zhao ${ }^{\mathrm{a}, \mathrm{b}, *}$, Shengbin Chen ${ }^{\mathrm{c}}$, Hua Wang ${ }^{\mathrm{d}}$, Yin Ren ${ }^{\mathrm{a}, \mathrm{b}}$, Ke Du ${ }^{\mathrm{e}}$, Weihua Xu ${ }^{\mathrm{f}}$, Hua Zheng ${ }^{\mathrm{f}}$, Bo Jiang ${ }^{\mathrm{f}}$ \\ ${ }^{a}$ Key Lab of Urban Environment and Health, Institute of Urban Environment, Chinese Academy of Sciences, 1799 Jimei Road, Jimei District, Xiamen 361021, China \\ ${ }^{\mathrm{b}}$ Xiamen Key Lab of Urban Metabolism, 1799 Jimei Road, Jimei District, Xiamen 361021, China \\ ${ }^{\mathrm{c}}$ Nanjing Institute of Environmental Sciences, Ministry of Environmental Protection, Nanjing 210042, China \\ d Institute of Forestry and Pomology, Beijing Academy of Agriculture and Forestry Sciences, Beijing 100093, China \\ e Institute of Urban Environment, Chinese Academy of Sciences, Xiamen, China \\ ${ }^{\mathrm{f}}$ State Key Laboratory of Urban and Regional Ecology, Research Center for Eco-Environmental Sciences, Chinese Academy of Sciences, Beijing 100085, China
}

\section{A R T I C L E I N F O}

\section{Article history:}

Received 16 November 2011

Received in revised form

1 April 2012

Accepted 8 April 2012

\section{Keywords:}

Socio-economic factors

Air quality

Urban environment

Urbanization

Variation partitioning

Environmental treatment

\begin{abstract}
A B S T R A C T
Socio-economic factors have significant influences on air quality and are commonly used to guide environmental planning and management. Based on data from 85 long-term daily monitoring cities in China, air quality as evaluated by AOFDAQ-A (Annual Occurrence Frequency of Daily Air Quality above Level III), was correlated to socio-economic variable groups of urbanization, pollution and environmental treatment by variation partitioning and hierarchical partitioning methods. We found: (1) the three groups explained $43.5 \%$ of the variance in AOFDAQ-A; (2) the contribution of "environmental investment" to AOFDAQ-A shown a time lag effect; (3) "population in mining sector" and "coverage of green space in built-up area" were respectively the most significant negative and positive explanatory socioeconomic variables; (4) using eight largest contributing individual factors, a linear model to predict variance in AOFDAQ-A was constructed. Results from our study provide a valuable reference for the management and control of air quality in Chinese cities.
\end{abstract}

(c) 2012 Elsevier Ltd. All rights reserved.

\section{Introduction}

Urban areas are hot spots that drive environmental change (Grimm et al., 2008). The unprecedented rate of urban growth over the past century has had an enormous global impact (Brown, 2001). Although cities only cover $2.8 \%$ of the Earth's terrestrial surface, they are the major consumers of natural resources, the major producers of pollution waste, and the focus of most other human activities, many governments realize that much of the sustainability debate has an urban focus (Breheny, 1992; Marquez and Smith, 1999).

As cities are wholly created by humans (Whitney and Adams, 1980; Hope et al., 2003), the ecology and environment in and around cities reflects social, economic, and cultural influences (Liu, 2001). For example, income and education are robust determinants of household air pollution (Papineau et al., 2009), urban population density can influence total passenger vehicle emissions (Marshall et al., 2005), and economic development has positive contribution to environmental quality (Xepapadeas and Amri, 1998).

\footnotetext{
* Corresponding author.

E-mail addresses: jjzhao@iue.ac.cn, zhao.juanjuan.cn@gmail.com (J. Zhao).
}

However, other reports found that when GDP increases, the larger scale of production leads directly to more pollution and more environmental damage (Zugravu et al., 2008). After all, according to Ewing et al. (2007), compact development could achieve a reduction of greenhouse gas emissions by up to $10 \%$ by 2050 . Moreover, additional reductions may result from employing other strategies such as transit investment, fuel pricing, and parking (Bandeira et al., 2011).

In light of these significant influences of socio-economic factors, cities should be designed and managed to reduce environmental degradation (Marquez and Smith, 1999). At least $24 \%$ of greenhouse gas emissions sources are amenable via more enlightened urban planning and design principles and programs, increasing to $54 \%$ if transport, housing and commercial buildings are included (Marquez and Smith, 1999). Information is then needed on the technological and planning options available and how much these can help to reduce emissions and at what cost (Mediavilla-Sahagun and ApSimon, 2006). By determining their power to explain the variance in air quality, socio-economic indices could be more practically and expediently used to connect air quality control with urban planning and policy making. Such an approach should be transparent to both the responsible authorities and to the affected public (Mediavilla-Sahagun and ApSimon, 2006). Yet relative 
studies on the contribution of policy and planning to explain the variance in air quality have only been sporadically reported (Bandeira et al., 2011).

Air pollution in Chinese cities has become one of the top environmental concerns. As a typical developing country, China has an urban population of 621.86 million, accounting for $46.56 \%$ of the total population (Editorial Board of China Statistical Yearbook, 2010). In the last two decades, knowledge on air pollution has improved considerably as funding for environmental research has increased (Florig et al., 2002; Chan and Yao, 2008). Air quality monitoring systems have been installed in over 200 cities, some of which began monitoring in the year 2000, and the number of monitored cities continues to increase. The daily reports of air quality in the monitored cities provide important basic data for air quality research.

Socio-economic factors are always important in macro-control of national environmental pollution, and are used to guide environmental treatments. In this research, we hypothesized that air quality in cities is affected by the interrelated socio-economic factors that characterize the human disturbance. The air quality of 85 cities covering all provinces in mainland China with the exception of Tibet were assessed with respect to 21 environmental factors divided into three groups i.e. urbanization, pollution and environmental treatment. Specifically, we posted the following research questions: (1) Do the methods of partitioning analysis applicable to distinguish the relative importance of socio-economic variable groups to air quality? (2) To what extents the contributions of pollution, urbanization and environmental treatment account for variations in urban tree transpiration? (3) Which socio-economic variables are the most important predictors of urban air quality? The results from this research provide insights into the causal socio-economic variables of urban air quality, and provide valuable references for the management and control of air quality in Chinese cities.

\section{Materials and methods}

\subsection{Study sites}

Air quality samples were collected at 85 long-term daily monitoring sites (see Appendix A), covering all provinces in mainland China with the exception of Tibet, for which socio-economic data were unavailable. Most of the monitoring sites were in relatively developed cities in each province. The location and monitoring effort for each site is shown in the Appendix A. A map showing the distribution of these sites in China can be seen in the Ministry of Environmental Protection of the People's Republic of China website (MEPPRC, http://www.zhb.gov.cn; Chinese National Environmental Monitoring Centre, 2010). As monitoring at different sites began at different times, the monitoring periods also varies between sample sites (see Appendix A).

\subsection{Data}

\subsubsection{Air quality}

To quantify air quality, an air pollution index (API; National Bureau of Statistics of China, 2008) has been in use at the monitoring sites since 1997. Daily average API values of all the monitoring cities are reported at the official website (http://www. zhb.gov.cn). Based on the API, ambient air quality of monitored cities are classified into five levels and also reported on the MEPPRC website (Table 1). These reports provide overviews of air quality across mainland China.

API reporting requires monitored daily average air quality data to be converted into integer values (Jiang et al., 2004). API is measured as the maximum pollution sub-index of pollutants by the following formula (National Bureau of Statistics of China, 2008):

$\mathrm{API}=\operatorname{Max}\left\{I_{1}, I_{2} \ldots I_{x} \ldots I_{n}\right\}$

where $I_{X}$ is the air pollution index for pollutant $\mathrm{X}$, and $n$ is the number of pollutants. For pollutant $\mathrm{X}, I_{X}$ is calculated by the following formula:

$I_{x}=\frac{\left(C_{X}-C_{x . j}\right)}{C_{x . j+1}-C_{x . j}}\left(I_{x . j+1}-I_{x . j}\right)+I_{x . j}$

Where $C_{x . j}<C_{x} \leq C_{x . j+1}, C_{\mathrm{x}}$ is the concentration of pollutant $\mathrm{X}\left(\mathrm{mg} / \mathrm{m}^{3}\right), C_{x . j}$ is the threshold concentration of pollutant $X$ for level $j$ that is $\leq C_{x}, C_{x . j+1}$ is the threshold concentration for level $j+1$ that is $\geq C_{X}, I_{x . j}$ is the index of pollutant $\mathrm{X}$ for level $j$, and $I_{x, j+1}$ is the index for level $j+1$.

For the indices for different levels of pollutants, see the published technical manual for urban ambient air quality daily report and forecast in China (National Bureau of Statistics of China, 2008).

The pollutants in the daily report include daily average concentrations of $\mathrm{SO}_{2}$ $\mathrm{NO}_{2}, \mathrm{PM}_{10}$ and $\mathrm{CO}$, and eight hour (9:00-17:00) averaged concentration of $\mathrm{O}_{3}$ (National Bureau of Statistics of China, 2008). Since the API is simply the maximum value of the normalized concentrations at a given site, the various pollutants are ascribed equal importance in describing the overall air quality (Liu and Chan, 2002). Technical details concerning the monitoring sites, monitoring methods and statistical methods have been described in Automatic Monitoring Technical Specifications of Ambient Air Quality (HJ/T 193-2005; National Bureau of Statistics of China, 2005a), and Manual Monitoring Technical Specifications of Ambient Air Quality (HJ/T 194-2005; National Bureau of Statistics of China, 2005b).

The Annual Occurrence Frequency of Daily Air Quality above Level III (including air quality level I and II, abbreviated as AOFDAQ-A, and not poor air quality levels III, IV and V), which means better air quality when outdoor activity is not affected, is widely used in China for governmental planning and scientific research. In this paper we took daily air quality observation records from 2000 to 2009 (Chinese National Environmental Monitoring Centre, 2010), and calculated the AOFDAQ-A for each city in each year by dividing the total number of days with daily air quality better than level III by the number of days with valid observations.

\subsubsection{Socio-economic variables}

Socio-economic predictor variables data was collected from the Statistics Yearbook of Cities in China (Urban Socio Economic Survey Division of National Bureau of Statistics of China, 2001-2010). All possible socio-economic predictor factors were tested using linear regression to select those with a significant effect on air quality. According to the results, significant variables were classified into three groups, which are urbanization, pollution and environmental treatment (Table 2). We identified urbanization variables as a separate group because they were related to both pollution and environmental treatment. Where variables were recorded for different periods of time, data were analyzed during separate runs.

\subsubsection{Linear regression}

Linear regressions were conducted for each explanatory variable to select the significant variables. For each of the linear regressions, an approximately normal distribution of the residuals was proved by QQ-plot of model residuals and boxplot of residuals, and Levene's test was used to test for homogeneity of variances for the residuals.

Using SPSS16.0, a multi-variables linear regression was conducted with the eight most significant and least collinear variables to model the value of AOFDAQ-A. The error term had a normal distribution with a mean of $<0.001$.

Table 1

Classification criteria of air quality (translated from National Bureau of Statistics of China, 2008)

\begin{tabular}{|c|c|c|c|c|}
\hline $\begin{array}{l}\text { Air quality } \\
\text { index (API) }\end{array}$ & $\begin{array}{l}\text { Air quality } \\
\text { level }\end{array}$ & $\begin{array}{l}\text { Air quality } \\
\text { condition }\end{array}$ & At risk population & Health implications \\
\hline $0-50$ & I & Excellent & Usual outdoor activities & None \\
\hline $51-100$ & II & Good & & \\
\hline $101-200$ & III & Lightly polluted & $\begin{array}{l}\text { Mild aggravation of symptoms among susceptible persons. } \\
\text { Generally healthy individuals may also notice some discomfort. }\end{array}$ & $\begin{array}{l}\text { People with breathing or heart problems should } \\
\text { restrict physical exercises and outdoor activities. }\end{array}$ \\
\hline $201-300$ & IV & $\begin{array}{l}\text { Moderately } \\
\text { polluted }\end{array}$ & $\begin{array}{l}\text { Moderate aggravation of symptoms and decreased tolerance in } \\
\text { persons with heart or lung disease. More widespread symptoms } \\
\text { of transient irritation in the healthy population. }\end{array}$ & $\begin{array}{l}\text { Elders and people with existing heart or respiratory } \\
\text { illnesses should remain indoors and avoid exercise. }\end{array}$ \\
\hline$>300$ & $\mathrm{~V}$ & $\begin{array}{l}\text { Intensively } \\
\text { polluted }\end{array}$ & $\begin{array}{l}\text { Healthy people may experience decreased exercise tolerance and } \\
\text { adverse symptoms that affect normal activity, in addition to early } \\
\text { onset of certain diseases. }\end{array}$ & $\begin{array}{l}\text { Elders and the sick should remain indoors and avoid } \\
\text { exercise. Healthy individuals should avoid outdoor } \\
\text { activities. }\end{array}$ \\
\hline
\end{tabular}


Table 2

Statistical inferences of variation partitioning on explanatory variables showing their effects on air quality.

\begin{tabular}{|c|c|c|c|}
\hline \multirow[t]{2}{*}{ Variable groups } & \multirow[t]{2}{*}{ Variables } & \multicolumn{2}{|c|}{ Adjusted $R$ square } \\
\hline & & Linear & Quadratic \\
\hline \multirow[t]{5}{*}{ Urbanization variables } & Service industry as percent of GDP (SIP) & $0.0360^{* * a}$ & $0.0359^{* *}$ \\
\hline & Rural population (RP) & $0.0562^{* *}$ & $0.0959^{* *}$ \\
\hline & Built-up area (BA) & $0.0423^{* *}$ & $0.0424^{* *}$ \\
\hline & Land area for urban construction (LAU) & $0.0226^{* *}$ & $0.0226^{* *}$ \\
\hline & Urban population density (UPD) & $0.0257^{* *}$ & $0.0256^{* *}$ \\
\hline \multirow[t]{8}{*}{ Pollution variables } & Population in building industry sector (PBI) & $0.0981^{* *}$ & $0.0980^{* *}$ \\
\hline & Population in real estate sector (PRE) & $0.0149 * *$ & $0.0150^{* *}$ \\
\hline & Population in transport, storage and post sectors (PTS) & $0.0767^{* *}$ & $0.0779^{* *}$ \\
\hline & Population in mining sector (PMiS) & $0.1053^{* *}$ & $0.0941^{* *}$ \\
\hline & Population in manufacturing sector (PMaS) & $0.0373^{* *}$ & $N S^{b}$ \\
\hline & Residential consumption of coal gas (RCC) & $0.1132^{* *}$ & $0.1132^{* *}$ \\
\hline & Total supply of coal gas (TSC) & $0.1282^{* *}$ & $0.1281^{* *}$ \\
\hline & Population in the sector for production and supply of electricity, gas and water (PSP) & $0.1525^{* *}$ & $0.1325^{* *}$ \\
\hline \multirow[t]{8}{*}{ Environmental treatment variables } & Total investment in environmental pollution control as percent of GDP (TIE) & $0.0110^{* c}$ & NS \\
\hline & Area of green space in parks (AGS) & $0.0122^{* * \mathrm{c}}$ & $0.0122^{* *}$ \\
\hline & Coverage of green space in built-up area (CGS) & $0.1316^{* *}$ & $0.1147^{* *}$ \\
\hline & Ratio of industrial solid wastes utilized (RISw) & $0.0767 * *$ & $0.0772^{* *}$ \\
\hline & Ratio of industrial waste water meeting discharge standards (RIW) & NS & $0.0062^{*}$ \\
\hline & Ratio of industrial $\mathrm{SO}_{2}$ removed (RISr) & NS & $0.0673^{* *}$ \\
\hline & Treatment rate of urban consumption waste water (TRU) & $0.0071^{*}$ & $0.0042^{* *}$ \\
\hline & Treatment rate of consumption wastes (TRC) & $0.0364^{* *}$ & $0.0370^{* *}$ \\
\hline
\end{tabular}

a,c “*** and "**" indicate inferences are significant at $p<0.01$ and $p<0.05$ respectively.

bymbols "NS" denotes no effects; for each of the significant variables, the $p$-value of intercept and slope are significant at $p<0.05$.

\subsection{Variation partitioning for variable groups}

Variation partitioning was used to decompose the variation in air quality following the methods described by Anderson and Gribble (1998), Heikkinen et al. (2004, 2005), and Wang et al. (2011). This partitions the variance of AOFDAQ-A into eight fractions, namely the individual effects of urbanization, pollution, and environmental treatment, respectively; joint effects of urbanization and pollution, urbanization and environmental treatment, and pollution and environmental treatment respectively; joint effects of the three explanatory variable groups; and finally unexplained variance. To improve the comparability and the linearity of relationships between predictor variables and air quality, the socio-economic data was log-transformed.

The first step was to perform a series of linear regression for all socio-economic variables, using an R statistical package ('hier.part package' version 0.5-1, Walsh and Mac-Nally, 2003). Explanatory variables that did not contribute significantly to the variance of AOFDAQ-A at $p>0.05$ (Borcard et al., 1992; Wang et al., 2011) were excluded. Quadratic terms of predictors were also analyzed in this procedure to take potential curvilinear relationships into account (Heikkinen et al., 2004; Wang et al., 2011). Only significant predictor variables identified in this process were included in the subsequent analyses. The other three steps to calculate the value of the eight fractions followed Wang et al. (2011).

\subsection{Hierarchical partitioning for individual variables}

Hierarchical partitioning aims at generating a detailed basis for inferring causality in multivariate regression settings (Watson and Peterson, 1999). To identify the contribution of individual variables that significantly affected air quality, hierarchical partitioning was conducted using $\mathrm{R}$ statistical package (Walsh and MacNally, 2003). The functions in this package produce a minor rounding error for analyses with more than nine independent variables (Walsh and Mac-Nally, 2003), so the eight most significant and least collinear variables were selected to perform hierarchical partitioning. The partitioning was conducted using linear regression with $R^{2}$ as the goodness-of-fit measure.

Hierarchical partitioning depends on the existence of monotonic relationships between the response and the predictor variables (Heikkinen et al., 2004). Hence, for those variables which were only significant in quadratic terms, the quadratic terms were entered into the partitioning to improve the linearity of relationships between air quality and socio-economic variables (Wang et al., 2011).

In addition, following Mac-Nally (2002), statistical significances of the independent contributions of variables were tested by a randomization routine, which yielded $Z$-scores for the generated distribution of randomized independent contributions, and a measure of statistical significance $\left({ }^{*}\right)$ based on an upper 0.95 confidence limit (Heikkinen et al., 2005).

As a result, hierarchical partitioning provides, for each explanatory variable separately, an estimate of the independent and joint contribution with all other variables (Heikkinen et al., 2005; Chevan and Sutherland, 1991; Mac-Nally, 2000; Quinn and Keough, 2002).

\section{Results}

\subsection{Air quality and annual variation trend}

For most monitoring sites, the air quality in Chinese cities appeared to improve during the ten year period (Figs. 1 and 2). During the period 2000-2002, AOFDAQ-A below 60\% occurred in $19.1 \%-27.7 \%$ of cities, dropping to $8.5 \%$ and $7.1 \%$ of cities in 2003 and 2004 , then to $1.2 \%$ of cities in 2005-2006, and finally disappearing in the period 2007-2009 (Fig. 1). On the contrary, AOFDAQ-A above $80 \%$ exhibited an upwards trend, increasing from $46.8 \%-59.5 \%$ of cities in the first three years, to $63.8 \%-77.9 \%$ of cities in the following four years, and to $83.7 \%-95.3 \%$ of cities in the last three years (Fig. 1).

The highest AOFDAQ-A appeared in Zhuhai, Zhanjiang, Haikou, Guilin and Beihai, with $100 \%$ occurrence in nine or ten years. Some other cities had 95\% occurrence of daily air quality above level III, including Kunming, Nanning, Xiamen, Shantou, Shenzhen, Wenzhou, and Yantai. Overall, the AOFDAQ-A for most cities during most years was higher than $80 \%$, with the exceptions being Beijing, Lanzhou and Urumqi. On the whole, air quality of cities in the south of China was much better than in northern cities.

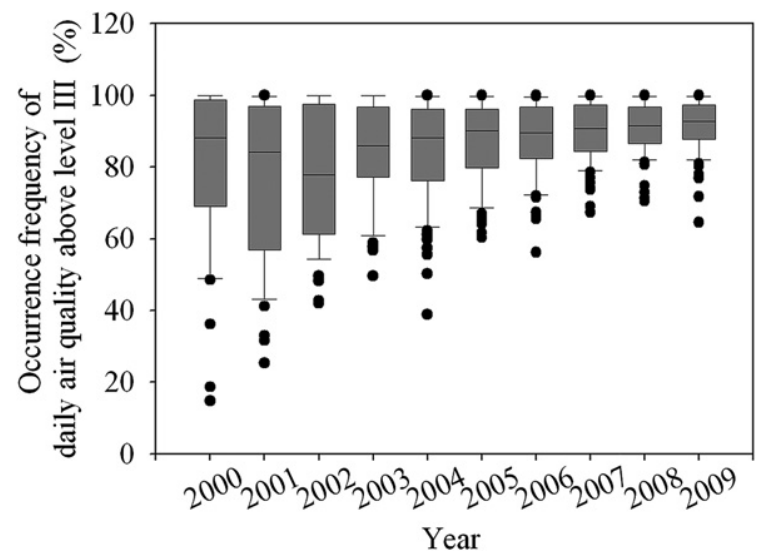

Fig. 1. Overview of air quality in the monitoring cities from 2000 to 2009. In 2000, 42 cities were monitored; from 2001 to 2003, 47 cities were monitored; from 2004 to 2005, 84 cities were monitored; from 2006 to 2009, 86 cities were monitored. 


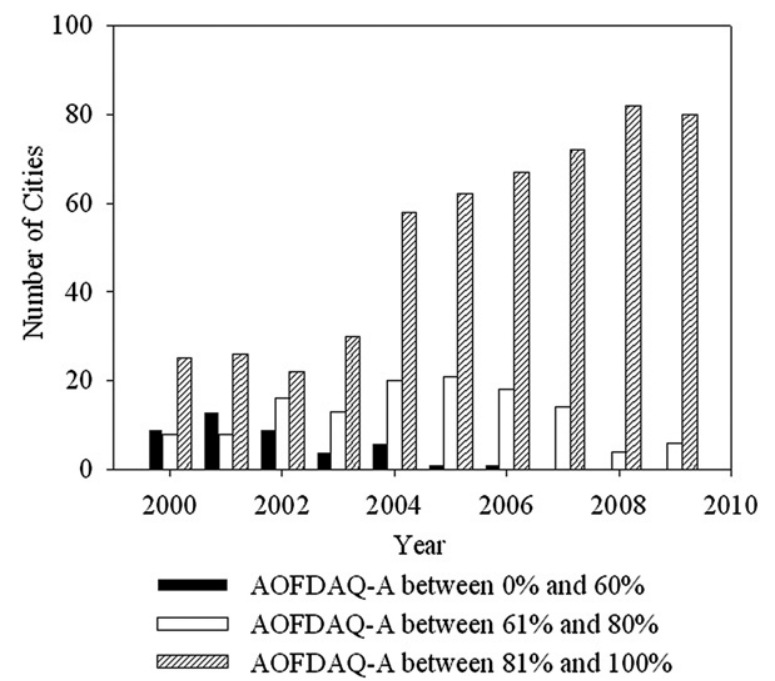

Fig. 2. Variation trend of air quality in the monitoring cities from 2000 to 2009 . A boxplot is a graphical summary of a distribution. The box itself contains the middle $50 \%$ of the data. The upper edge (hinge) of the box indicates the 75th percentile of the data set, and the lower hinge indicates the 25th percentile. The line in the box indicates the median value of the data. The error bars represent the 5th and 95th percentile values. The points outside the ends of the whiskers are outliers or suspected outliers.

\subsection{The relationship between air quality and socio-economic variables}

By linear regression, 21 significant variables were identified from 72 possible explanatory variables, and divided into three groups according to their influence on air quality (Table 2). All three variable groups were found to contribute significantly to the variance of AOFDAQ-A. Five variables were included in the urbanization group, and there were eight variables in both the pollution group and the environmental treatment group. Most of the variables were significant contributors both in linear and quadratic terms. When both linear and quadratic terms were significant, the linear terms were used in subsequent analyses. The urbanization variables and the pollution variables were negatively related to AOFDAQ-A, while most of the environmental treatment variables had positive effects on AOFDAQ-A, with the exception of "area of green space in parks".

\subsection{Relative effect of urbanization, pollution and environmental treatment}

When the variance of AOFDAQ-A was decomposed, the pollution group had the primary influence on air quality, with an independent contribution of $16.6 \%$. The environmental treatment group and the urbanization group, respectively contributed $4.5 \%$ and $1.7 \%$ to the variance. The independent and joint contributions of the three groups accounted for $43.5 \%$ variance of AOFDAQ-A.

Joint effects were also considerable. The largest joint effect was contributed by the three groups combined, which accounted for $9.4 \%$ of the variance (Table 3 ). The joint effect of the pollution and environmental treatment groups was also relatively large (6.8\%). The joint effect of the urbanization and pollution groups, and joint effect of the urbanization and environmental treatment groups, however were relatively minor, at $3.2 \%$ and $1.3 \%$ respectively.

\subsection{Relative effects of individual variables}

After linear regression for all individual socio-economic variables, the eight most significant variables were selected to perform a hierarchical partitioning. Among the eight most significant variables, "population in mining sector" exhibited the highest independent contribution to the variance of AOFDAQ-A, followed by "total supply of coal gas" and "ratio of industrial $\mathrm{SO}_{2}$ removed", respectively contributing $8.0 \%, 6.9 \%$ and $6.0 \%$ (Fig. 3). The largest joint contribution appeared in "population in building industry sector", "total supply of coal gas" and "coverage of green space in built-up area", respectively $6.2 \%, 6.1 \%$ and $6.1 \%$ (Fig. 3).

Only three of the eight variables made a positive contribution to the variance of AOFDAQ-A. The variance explained by "coverage of green space in built-up area" was the highest, followed by "ratio of industrial solid wastes utilized" (7.5\%) and "ratio of industrial $\mathrm{SO}_{2}$ removed" (6.9\%).

\subsection{Multi-linear regression for a model of AOFDAQ-A}

By linear regression, a model was constructed using the eight most significant variables as follows:

$$
\begin{aligned}
y= & 58.671+5.908 b_{1}+20.103 b_{2}+6.276 b_{3}+0.002 b_{4} \\
& -2.529 b_{5}-7.505 b_{6}-4.256 b_{7}-2.505 b_{8}
\end{aligned}
$$

where $y$ is AOFDAQ-A, $b_{1-8}$ are the variables shown in Table 4 .

According to the results of the linear regression, all coefficients were significant and the variables were indicated to make significant contributions to the model. As a whole, modeling of AOFDAQA was desirable. The $R$ value of 0.634 indicated a strong relationship between the variables and AOFDAQ-A, and the squared $R$ value was 0.402 , meaning that nearly half the variation in AOFDAQ-A was explained by the model. The VIF (variance inflation factor) values were mostly smaller than 2 , so the multi-collinearity was low and the standard error of the regression coefficients would not be significantly inflated (Table 4).

\section{Discussion}

Air quality in cities generally deteriorates as population, traffic, industrialization and energy use increase (Mayer, 1999). However, only limited studies have been conducted to investigate the complex relationship between urban air quality and socio-economic factors. In this paper, our study yielded contrasting inferences about the relative importance of socio-economic variables to influence air quality. Some of the results provided basic information for the control and management of urban air quality in China.

The pollution group, with an independent contribution of $16.6 \%$, accounted for the largest proportion of variance in air quality among the three groups. It is notable that although the populations of pollution-related industrial sectors are rarely used to represent pollution intensity, six of the eight significant variables in the pollution group were related populations. Since the size of the industrial sectors are likely to be correlated to respective population

Table 3

\begin{tabular}{|c|c|c|c|c|c|c|c|c|}
\hline & $\mathrm{a}\left(\mathrm{U}^{\mathrm{a}}\right)$ & $\mathrm{b}\left(\mathrm{P}^{\mathrm{b}}\right)$ & $c\left(E^{c}\right)$ & $\mathrm{d}(\mathrm{U} \times \mathrm{E})$ & $e\left(U \times{ }^{d} E\right)$ & $f(P \times E)$ & $\mathrm{g}(\mathrm{U} \times \mathrm{P} \times \mathrm{E})$ & h (Unaccounted) \\
\hline Relative effects & $1.7 \%$ & $16.6 \%$ & $4.5 \%$ & $3.2 \%$ & $1.3 \%$ & $6.8 \%$ & $9.4 \%$ & $56.5 \%$ \\
\hline
\end{tabular}

Relative effects of variable groups on air quality.

a "U" denotes urbanization group.

b "P" denotes pollution group.

c "E" denotes environmental treatment group.

$\mathrm{d}$ " $\times$ " denotes joint effect of relative groups. 


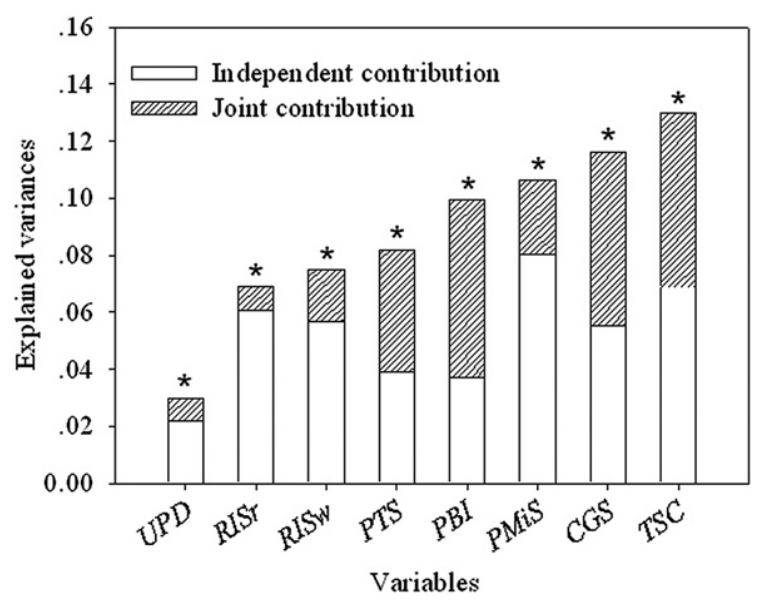

Fig. 3. Contributions to the variance of AOFDAQ-A by the eight most significant variables in which "*" denotes the effect due to this variable is significant at $p<0.05$. All the variables were log-transformed, excepting RISr.

size, variables of population may be applicable as substitutes of industrial sizes when predicting the influences on air quality.

Although urbanization involves processes related to both pollution and environmental treatment, more negative effects are demonstrated in this research. During urbanization, pollution increases due to more intensive building construction, energy consumption and transportation, but greater environmental investments are also made possible by increased population and economic power. In this paper, our analyses indicate that urbanization had more negative than positive effects on air quality in Chinese cities. However, the total independent contribution was only $1.7 \%$, relatively small compared to the pollution group. Considering that the effects of urbanization on air quality are indirect and that different urbanization policies and planning might imply different influences, further researches on more systematic analyses of urbanization effects should be conducted.

"Coverage of green space in built-up area" was demonstrated to be the most important positive variable for air quality in urban China. This finding is in agreement with some earlier reports. Urban vegetation was found to play an important role in decomposing and mitigating air pollution by Beckett et al. (1998) and Nowak and Crane (2000). Additional vegetation cover in urban areas may decrease the concentrations of air-pollutants and their outflow by reducing energy demand and biogenic emissions in surrounding areas (Civerolo et al., 2000). However the significance of the air-pollutant uptake by urban vegetation has been questioned by other researchers. Escobedo and Nowak (2009) reported that less than $2 \%$ of particles with a diameter of 10 microns or less $\left(\mathrm{PM}_{10}\right)$ were removed in areas with the highest tree cover (26\%). After all, our results suggest that improving green space is an important approach to improve air quality in Chinese cities. However, since a correlation does not necessarily prove a cause and an effect, other factors which were not analyzed in this study may influence the effect of green space on air quality.

However, another significant index of green space, the "area of green space in parks" was negatively related to air quality, which tends to support the remarks of Escobedo and Nowak (2009). The ecological functions of green spaces in cities are complex (Pataki et al., 2011). In China, most green spaces in parks are relatively artificial and intensively cultivated (Zhao et al., 2010b). To attract more visitors, park management often plant novel alien plants and large areas of lawn, which require a great amount of maintenance and thus lead to much more energy consumption and pollution emissions. Managers should therefore encourage the growth of more natural vegetation, especially trees, to improve the ecological functions of park green spaces.

The contribution of environmental investment to air quality was surprisingly low. It is possible that this is due to a time lag effect, after which the benefits of the investment begin to exhibit. To inspect time lag effects, environmental investments were analyzed with air quality of each of the three years following the investments. As shown in Table 5, environmental investment as percentage of GDP contributed only $1 \%$ yet significantly, to the variance in AOFDAQ-A after one year. However, the effects increased during following years, and had doubled by the third year after the investments were made. It seems that the existence of a time lag effect is therefore confirmed. To evaluate the contribution of environmental investments to air quality, time lag effects should be accounted for.

The relatively weak effects of environmental investments may also be attributed to the inadequate intensity and efficiency of investment. Although environmental protection has become an important concern for the national government, as a densely populated developing country, it is difficult for China to find the right balance between economic development and environmental protection (Fang et al., 2009). Although the environmental investments by cities above prefecture level increased from $1.6 \pm 2.6$ (average \pm standard deviation) billion yuan in 2002 to $2.6 \pm 5.2$ billion yuan in 2007, the amount of environmental investment remains relatively low, and greater and more effective investment may be required to achieve better results. Moreover, the investment pattern may also be important to efficiently improve air quality. Because the air quality index used in this paper treated various pollutants as equally important, if only some of the pollutants were targeted by pollution control efforts, other high concentration pollutants might still decrease the air quality value (API).

Other factors that were not discussed in this paper may also contribute to overall air quality, including meteorological conditions (Barman et al., 2008; Cermak and Knutti, 2009; Wang et al., 2009; Ren et al., 2011), topographical influences, emission sources (Wang et al., 2010), transport from the stratosphere and long-range transport (Zhao et al., 2010a). Further examination of all these variables could improve ability to predict variance in air quality. In

Table 4

Results of multi-linear regression of AOFDAQ-A.

\begin{tabular}{|c|c|c|c|c|c|}
\hline \multirow[t]{2}{*}{ Model } & \multirow[t]{2}{*}{ Label for variables } & \multirow{2}{*}{$\frac{\text { Un-standardized coefficients }}{B \text { value }}$} & \multirow{2}{*}{$\begin{array}{l}\text { Standardized coefficients } \\
\text { Beta }\end{array}$} & \multirow{2}{*}{$\frac{\text { Collinearity statistics }}{\text { VIF (variance inflation factor) }}$} & \multirow[t]{2}{*}{ Sig. } \\
\hline & & & & & \\
\hline (Constant) & & 58.671 & & & $<0.001$ \\
\hline Population in building industry sector ${ }^{\mathrm{a}}$ & $b_{1}$ & 5.908 & 0.140 & 3.098 & 0.026 \\
\hline Coverage of green space in built-up area ${ }^{a}$ & $b_{2}$ & 20.103 & 0.196 & 1.114 & $<0.001$ \\
\hline Ratio of industrial solid wastes utilized ${ }^{\mathrm{a}}$ & $b_{3}$ & 6.276 & 0.201 & 1.183 & $<0.001$ \\
\hline Ratio of industrial $\mathrm{SO}_{2}$ removed & $b_{4}$ & 0.002 & 0.250 & 1.056 & $<0.001$ \\
\hline Total supply of coal gas $\mathrm{a}$ & $b_{5}$ & -2.529 & -0.243 & 1.344 & $<0.001$ \\
\hline Population in mining sector ${ }^{\mathrm{a}}$ & $b_{6}$ & -7.505 & -0.219 & 1.133 & $<0.001$ \\
\hline Population in transport, storage and post sectors ${ }^{\mathrm{a}}$ & $b_{7}$ & -4.256 & -0.311 & 3.269 & $<0.001$ \\
\hline Population density ${ }^{\mathrm{a}}$ & $b_{8}$ & -2.505 & -0.145 & 1.112 & $<0.001$ \\
\hline
\end{tabular}

\footnotetext{
${ }^{\text {a }}$ Variables are ln-transformed.
} 
Table 5

Linear regression results of environmental investments with different span of time lag.

\begin{tabular}{lllll}
\hline Time lag & Adjusted $R^{2}$ & $p$-value & $p r$ value of Levene's test & Slope \\
\hline Three years & 0.0202 & 0.0023 & 1 & 0.6096 \\
Two years & 0.0136 & 0.0104 & 0.9995 & 0.5826 \\
One year & 0.0108 & 0.02 & 0.9611 & 0.5992 \\
Zero year & 0.011 & 0.0193 & 0.9137 & 0.7248 \\
\hline
\end{tabular}

addition, air quality is only one of the factors describing the environmental quality of a city, so studies on other environmental risks may be important for the overall environmental quality and sustainable development of cities.

\section{Conclusion}

By sampling cities covering most provinces in mainland China, it was found that air quality improved during the period 2000-2009. By linear regression, 21 significant variables were identified from 72 possible explanatory variables, and the relative effects on air quality were quantified. With an independent contribution of $16.6 \%$, the pollution group had a primary influence on air quality (AOFDAQ-A). All the five indexes of urbanization exhibited a negative relationship with air quality. Among the independent variables, "population of mining subsector" and "coverage of green space in built-up area" were respectively the most significant negative and positive explanatory variables, both contributing more than $12 \%$ of explained variance in AOFDAQ-A. However, environmental investments show time lag effects and did not have a large contribution to explain variance in AOFDAQ-A. Finally, when applied with caution, air quality studies in general would benefit from a wider application of partitioning methods. Whether the variation in air quality is ultimately more causally related to the significant variables would be further confirmed by experimental work or by accumulating information from other similar study settings.

\section{Acknowledgments}

This study was supported by Public Interest Program of Chinese Ministry of Environmental Protection (No. 201009004), Fujian Provincial Science and Technology Project (2011Y0052), and Special Foundation of Key Lab of Urban Environment and Health, Chinese Academy of Sciences. We especially thank Jonathan Vause (Chinese Academy of Sciences) for his helpful language polishing and Dr. Zhiyun Ouyang (Chinese Academy of Sciences) for his valuable advices on data analysis. Finally, we are extremely grateful

Appendix A

Table A.1

List of sampled long-term monitoring cities in China.

\begin{tabular}{|c|c|c|c|c|c|}
\hline City & Province & Monitoring periods & City & Province & Monitoring periods \\
\hline Beijing & Beijing & $2000-2009$ & Jining & Shandong & $2004-2009$ \\
\hline Tianjin & Tianjin & $2000-2009$ & Taian & Shandong & 2004-2009 \\
\hline Shijiazhuang & Hebei & $2000-2009$ & Rizhao & Shandong & 2004-2009 \\
\hline Qinhuangdao & Hebei & $2001-2009$ & Zhengzhou & Henan & $2000-2009$ \\
\hline Taiyuan & Shanxi & $2000-2009$ & Kaifeng & Henan & $2004-2009$ \\
\hline Datong & Shanxi & $2004-2009$ & Pingdingshan & Henan & $2004-2009$ \\
\hline Yangquan & Shanxi & 2004-2009 & Wuhan & Hubei & $2000-2009$ \\
\hline Changzhi & Shanxi & $2004-2009$ & Jingzhou & Hubei & 2004-2009 \\
\hline Huhehaote & Neimenggu & $2000-2009$ & Changsha & Hunan & $2000-2009$ \\
\hline Chifeng & Neimenggu & $2004-2009$ & Changed & Hunan & 2004-2009 \\
\hline Shenyang & Liaoning & $2000-2009$ & Zhangjiajie & Hunan & $2004-2009$ \\
\hline Dalian & Liaoning & $2000-2009$ & Guangzhou & Guangdong & $2000-2009$ \\
\hline Anshan & Liaoning & $2004-2009$ & Shaoguan & Guangdong & $2004-2009$ \\
\hline Fushun & Liaoning & 2004-2009 & Shenzhen & Guangdong & $2000-2009$ \\
\hline Changchun & Jilin & $2000-2009$ & Zhuhai & Guangdong & 2000-2009 \\
\hline Haerbin & Heilongjiang & $2000-2009$ & Shantou & Guangdong & $2000-2009$ \\
\hline Qiqihaer & Heilongjiang & $2004-2009$ & Zhanjiang & Guangdong & $2000-2009$ \\
\hline Mudanjiang & Heilongjiang & $2004-2009$ & Nanning & Guangxi & $2000-2009$ \\
\hline Shanghai & Shanghai & $2000-2009$ & Liuzhou & Guangxi & $2004-2009$ \\
\hline Nanjing & Jiangsu & $2000-2009$ & Guilin & Guangxi & $2001-2009$ \\
\hline Suzhou & Jiangsu & $2000-2009$ & Beihai & Guangxi & $2001-2009$ \\
\hline Nantong & Jiangsu & $2000-2009$ & Haikou & Hainan & $2000-2009$ \\
\hline Lianyungang & Jiangsu & 2001-2009 & Chengdu & Sichuan & $2000-2009$ \\
\hline Yangzhou & Jiangsu & $2004-2009$ & Chongqing & Chongqing & $2000-2009$ \\
\hline Zhenjiang & Jiangsu & $2004-2009$ & Zigong & Sichuan & $2006-2009$ \\
\hline Hangzhou & Zhejiang & $2000-2009$ & Luzhou & Sichuan & 2004-2009 \\
\hline Ningbo & Zhejiang & $2001-2009$ & Deyang & Sichuan & $2004-2009$ \\
\hline Wenzhou & Zhejiang & $2000-2009$ & Mianyang & Sichuan & 2004-2009 \\
\hline Huzhou & Zhejiang & 2004-2009 & Nanchong & Sichuan & $2006-2009$ \\
\hline Shaoxing & Zhejiang & $2004-2009$ & Guiyang & Guizhou & $2000-2009$ \\
\hline Hefei & Anhui & $2000-2009$ & Kunming & Yunnan & $2000-2009$ \\
\hline Wuhu & Anhui & $2004-2009$ & Qujing & Yunnan & 2004-2009 \\
\hline Fuzhou & Fujian & $2000-2009$ & Yuxi & Yunnan & 2004-2009 \\
\hline Xiamen & Fujian & 2000-2009 & Xi'an & Shanxi & $2000-2009$ \\
\hline Quanzhou & Fujian & $2004-2009$ & Baoji & Shanxi & $2004-2009$ \\
\hline Nanchang & Jiangxi & $2000-2009$ & Weinan & Shanxi & $2004-2009$ \\
\hline Jiujiang & Jiangxi & $2004-2009$ & Lanzhou & Gansu & $2000-2009$ \\
\hline Jinan & Shandong & $2000-2009$ & Xining & Qinghai & $2000-2009$ \\
\hline Qingdao & Shandong & $2000-2009$ & Yinchuan & Ningxia & $2000-2009$ \\
\hline Zibo & Shandong & $2004-2009$ & Shizuishan & Ningxia & $2004-2009$ \\
\hline Zaozhuang & Shandong & $2004-2009$ & Urumqi & Xinjiang & $2000-2009$ \\
\hline Yantai & Shandong & $2000-2009$ & Kalamayi & Xinjiang & 2004-2009 \\
\hline Weifang & Shandong & $2004-2009$ & & & \\
\hline
\end{tabular}


for the anonymous reviewers and editors for constructive comments on earlier versions of the manuscript.

\section{References}

Anderson, M.J., Gribble, N.A., 1998. Partitioning the variation among spatial, temporal and environmental components in a multivariate data set. Australian Journal of Ecology 23 (2), 158-167.

Bandeira, J.M., Coelho, M.C., Sa, M.E., Tavares, R., Borrego, C., 2011. Impact of land use on urban mobility patterns, emissions and air quality in a Portuguese mediumsized city. Science of the Total Environment 409, 1154-1163.

Barman, S.C., Singh, R., Negi, M.P.S., Bhargava, S.K., 2008. Fine particles $\left(\mathrm{PM}_{2.5}\right)$ in residential areas of Lucknow city and factors influencing the concentration. Clean-Soil, Air, Water 36, 111-117.

Beckett, K.P., Freer-Smith, P.H., Taylor, G., 1998. Urban woodlands: their role in reducing the effects of particulate pollution. Environmental Pollution 99 (3), $347-360$.

Borcard, D., Legendre, P., Drapeau, P., 1992. Partialling out the spatial component of ecological variation. Ecology 73 (3), 1045-1055.

Breheny, M., 1992. Sustainable development and urban form: an introduction. In: Breheny, M. (Ed.), Sustainable Development and Urban Form. European Research in Regional Science, London.

Brown, L.R., 2001. Eco-economy: Building an Economy for the Earth. Earthscan Publication Ltd, London.

Cermak, J., Knutti, R., 2009. Beijing Olympics as an aerosol field experiment. Geophysical Research Letters 36 (10), L10806.1-L10806.6.

Chan, C., Yao, X., 2008. Air pollution in mega cities in China. Atmospheric Environment $42,1-42$.

Chevan, A., Sutherland, M., 1991. Hierarchical partitioning. American Statistician 45 (2), 90-96.

Chinese National Environmental Monitoring Centre, 2010. Environmental Daily Reports of Major Cities in China. http://datacenter.mep.gov.cn/.

Civerolo, K.L., Sistla, G., Rao, S.T., Nowak, D.J., 2000. The effects of land use in meteorological modeling: implications for assessment of future air quality scenarios. Atmospheric Environment 34 (10), 1615-1621.

Editorial Board of China Statistical Yearbook, 2010. China Statistical Yearbook 2010. China Statistical Press, Beijing.

Escobedo, F.J., Nowak, D.J., 2009. Spatial heterogeneity and air pollution removal by an urban forest. Landscape and Urban Planning 90, 102-110.

Ewing, R.H., Bartholomew, K., Winkelman, S., Walters, J., Chen, D., 2007. Growing Cooler: The Evidence on Urban Development and Climate Change. Urban Land Institute, Chicago, IL.

Fang, M., Chan, C., Yao, X., 2009. Managing air quality in a rapidly developing nation: China. Atmospheric Environment 43 (1), 79-86.

Florig, H.K., Sun, G., Song, G., 2002. Evolution of particulate regulation in Chinaprospects and challenges of exposure-based control. Chemosphere 49 (9), 1163-1174.

Grimm, N.B., Faeth, S.H., Golubiewski, N.E., Redman, C.L., Wu, J., Bai, X., Briggs, J.M., 2008. Global change and the ecology of cities. Science 319, 756-760.

Heikkinen, R.K., Luoto, M., Kuussaari, M., Pöyry, J., 2005. New insights into butterflyenvironment relationships using partitioning methods. Proceedings of the Royal Society B: Biological Sciences 272 (1577), 2203.

Heikkinen, R.K., Luoto, M., Virkkala, R., Rainio, K., 2004. Effects of habitat cover, landscape structure and spatial variables on the abundance of birds in an agricultural-forest mosaic. Journal of Applied Ecology 41 (5), 824-835.

Hope, D., Gries, C., Zhu, W., Fagan, W.F., Redman, C.L., Grimm, N.B., Nelson, A.L., Martin, C., Kinzig, A., 2003. Socioeconomics drive urban plant diversity. Proceedings of the National Academy of Sciences 100, 8788-8792.

Jiang, D., Zhang, Y., Hu, X., Zeng, Y., Tan, J., Shao, D., 2004. Progress in developing an ANN model for air pollution index forecast. Atmospheric Environment 38, 7055-7064

Liu, H., Chan, J.C.L., 2002. An investigation of air-pollutant patterns under sea-land breezes during a severe air-pollution episode in Hong Kong. Atmospheric Environment 36 (4), 591-601.

Liu, J., 2001. Integrating ecology with human demography, behavior, and socioeconomics: needs and approaches. Ecological Modelling 140,1-8.

Mac-Nally, R., 2000. Regression and model-building in conservation biology, biogeography and ecology: the distinction between-and reconciliation of- 'predictive' and 'explanatory' models. Biodiversity and Conservation 9 (5), 655-671.
Mac-Nally, R., 2002. Multiple regression and inference in ecology and conservation biology: further comments on identifying important predictor variables. Biodiversity and Conservation 11 (8), 1397-1401.

Marquez, L.O., Smith, N.C., 1999. A framework for linking urban form and air quality. Environmental Modelling and Software 14, 541-548.

Marshall, J.D., McKone, T.E., Deakin, E., Nazaroff, W.W., 2005. Inhalation of moto vehicle emissions: effects of urban population and land area. Atmospheric Environment 39, 283-295.

Mayer, H., 1999. Air pollution in cities. Atmospheric Environment 33 (24-25), 4029-4037.

Mediavilla-Sahagun, A., ApSimon, H.M., 2006. Urban scale integrated assessment for London: which emission reduction strategies are more effective in attaining prescribed $\mathrm{PM}_{10}$ air quality standards by 2005? Environmental Modelling and Software 21, 501-513.

National Bureau of Statistics of China, 2005a. Automatic Monitoring Technical Specifications of Ambient Air Quality (HJ/T 193-2005). National Bureau of Statistics of China, Beijing.

National Bureau of Statistics of China, 2005b. Manual Monitoring Technical Specifications of Ambient Air Quality (HJ/T 194-2005). National Bureau of Statistics of China, Beijing.

National Bureau of Statistics of China, 2008. Technical Requirements for Urban Ambient Air Quality Daily Report and Forecast. National Bureau of Statistics of China, Beijing.

Nowak, D.J., Crane, D.E., 2000. The urban forest effects (UFORE) model: quantifying urban forest structure and functions. In: Hansen, M., et al (Eds.), Integrated Tools for Natural Resources Inventories in the 21st Century. United States Department of Agriculture, Saint Paul Minnesota, pp. 714-720.

Papineau, M., Aunan, K., Berntsen, T., 2009. Distributional determinants of household air pollution in China. Environment and Development Economics 14 621-639.

Pataki, D.E., Carreiro, M.M., Cherrier, J., Grulke, N.E., Jennings, V., Pincetl, S., Pouyat, R.V., Whitlow, T.H., Zipperer, W.C., 2011. Coupling biogeochemical cycles in urban environments: ecosystem services, green solutions, and misconceptions. Frontiers in Ecology and the Environment 9, 27-36.

Quinn, G.P., Keough, M.J., 2002. Experimental Design and Data Analysis for Biologists. Cambridge University Press, Cambridge.

Ren, Y., Wei, X., Wei, X.H., Pan, J.Z., Xie, P.P., Song, X.D., Peng, D., Zhao, J.Z., 2011 Relationship between vegetation carbon storage and urbanization: a case study of Xiamen, China. Forest Ecology and Management 261, 1214-1223.

Urban Socio Economic Survey Division of National Bureau of Statistics of China 2001-2010. China City Statistical Yearbook. China Statistics Press, Beijing.

Walsh, C.J., Mac-Nally, R., 2003. Hierarchical Partitioning, R Project for Statistical Computing. http://cran.r-project.org/.

Wang, H., Ouyang, Z., Chen, W., Wang, X., Zheng, H., Ren, Y., 2011. Water, heat, and airborne pollutants effects on transpiration of urban trees. Environmental Pollution 159 (8-9), 2127-2137.

Wang, S., Zhao, M., Xing, J., Wu, Y., Zhou, Y., Lei, Y., He, K., Fu, L., Hao, J., 2010 Quantifying the air pollutants emission reduction during the 2008 Olympic games in Beijing. Environmental Science and Technology 44, 2490-2496.

Wang, W., Primbs, T., Tao, S., Simonich, S.L.M., 2009. Atmospheric particulate matter pollution during the 2008 Beijing Olympics. Environmental Science and Technology 43, 5314-5320.

Watson, D.M., Peterson, A.T., 1999. Determinants of diversity in a naturally fragmented landscape: humid montane forest avifaunas of Mesoamerica. Ecography 22 (5), 582-589.

Whitney, G.G., Adams, S.D., 1980. Man as a maker of new plant communities Journal of Applied Ecology 17 (2), 431-448.

Xepapadeas, A., Amri, E., 1998. Some empirical indications of the relationship between environmental quality and economic development. Environmental and Resource Economics 11, 93-106.

Zhao, C., Wang, Y.H., Yang, Q., Fu, R., Cunnold, D., Choi, Y., 2010a. Impact of East Asian summer monsoon on the air quality over China: view from space. Journal of Geophysical Research D. Atmospheres 115 (9), D09301.

Zhao, J., Ouyang, Z., Zheng, H., Zhou, W., Wang, X., Xu, W., Ni, Y., 2010b. Plant species composition in green spaces within the built-up areas of Beijing, China. Plant Ecology 209, 189-204.

Zugravu, N., Millock, K., Duchene, G., 2008. The Factors Behind $\mathrm{CO}_{2}$ Emission Reduction in Transition Economies. Fondazione Eni Enrico Mattei, Working Paper No. 58.2008, 217. 